\title{
Delivery Room Management of Asphyxiated Term and Near-Term Infants
}

\author{
Marlies Brucknera, b, c Gianluca Lista ${ }^{d}$ Ola D. Saugstad ${ }^{e, f}$
}

Georg M. Schmölzer ${ }^{a, b}, c$

aCentre for the Studies of Asphyxia and Resuscitation, Neonatal Research Unit, Royal Alexandra Hospital, Edmonton, AB, Canada; 'bepartment of Pediatrics, Faculty of Medicine and Dentistry, University of Alberta, Edmonton, AB, Canada; 'Division of Neonatology, Department of Pediatrics and Adolescent Medicine, Medical University of Graz, Graz, Austria; 'Division of Neonatology, Department of Pediatric, "V. Buzzi" Ospedale Dei Bambini, Milan, Italy; 'Department of Pediatric Research, Oslo University Hospital Rikshospitalet, University of Oslo, Oslo, Norway; ${ }^{\mathrm{f} A n n}$ and Robert H. Lurie Children's Hospital of Chicago, Northwestern University Feinberg School of Medicine, Chicago, IL, USA

\section{Keywords}

Asphyxia $\cdot$ Newborn $\cdot$ Delivery room $\cdot$ Resuscitation

\section{Abstract}

Approximately 800,000 newborns die annually due to birth asphyxia. The resuscitation of asphyxiated term newly born infants often occurs unexpected and is challenging for healthcare providers as it demands experience and knowledge in neonatal resuscitation. Current neonatal resuscitation guidelines often focus on resuscitation of extremely and/or very preterm infants; however, the recommendations for asphyxiated term newborn infants differ in some aspects to those for preterm infants (i.e., respiratory support, supplemental oxygen, and temperature management). Since the update of the neonatal resuscitation guidelines in 2015, several studies examining various resuscitation approaches to improve the outcome of asphyxiated infants have been published. In this review, we discuss current recommendations and recent findings and provide an overview of delivery room management of asphyxiated term newborn infants.

(c) 2021 The Author(s).

Published by S. Karger AG, Basel

\section{Introduction}

All newborn infants require basic interventions (i.e., drying and stimulation and keeping them warm) during their transition from fetal to neonatal life $[1,2]$. Approximately $5 \%$ of newborns (6-7 million worldwide per year) need breathing support $[1,2]$, and $0.1 \%$ of term infants and $10-15 \%$ of preterm infants (1.5-2.5 million worldwide) need cardiopulmonary resuscitation (CPR) [3-6], defined as chest compressions, $100 \%$ oxygen, and/or epinephrine (adrenaline) in the delivery room (DR). Despite receiving CPR, about 800,000 newborns die annually worldwide due to birth asphyxia or intrapartum events. There are a number of causes of birth asphyxia or intrapartum events including poor antenatal healthcare as well as maternal, placental/umbilical, and neonatal issues [713] (Table 1).

Birth asphyxia is a condition of impaired gas exchange and lack of perfusion of various organs, which leads to progressive hypoxia, hypercarbia, and metabolic acidosis [9]. Asphyxia is a leading cause of neonatal death and disability. By introducing air instead of $100 \%$ oxygen of term or near-term newborns in need of positive pressure ven-
(C) 2021 The Author(s).

Published by S. Karger AG, Basel

This is an Open Access article licensed under the Creative Commons Attribution-NonCommercial-4.0 International License (CC BY-NC) (http://www.karger.com/Services/OpenAccessLicense), applicable to the online version of the article only. Usage and distribution for commercial purposes requires written permission.
Correspondence to:

Georg M. Schmölzer, georg.schmoelzer@me.com 


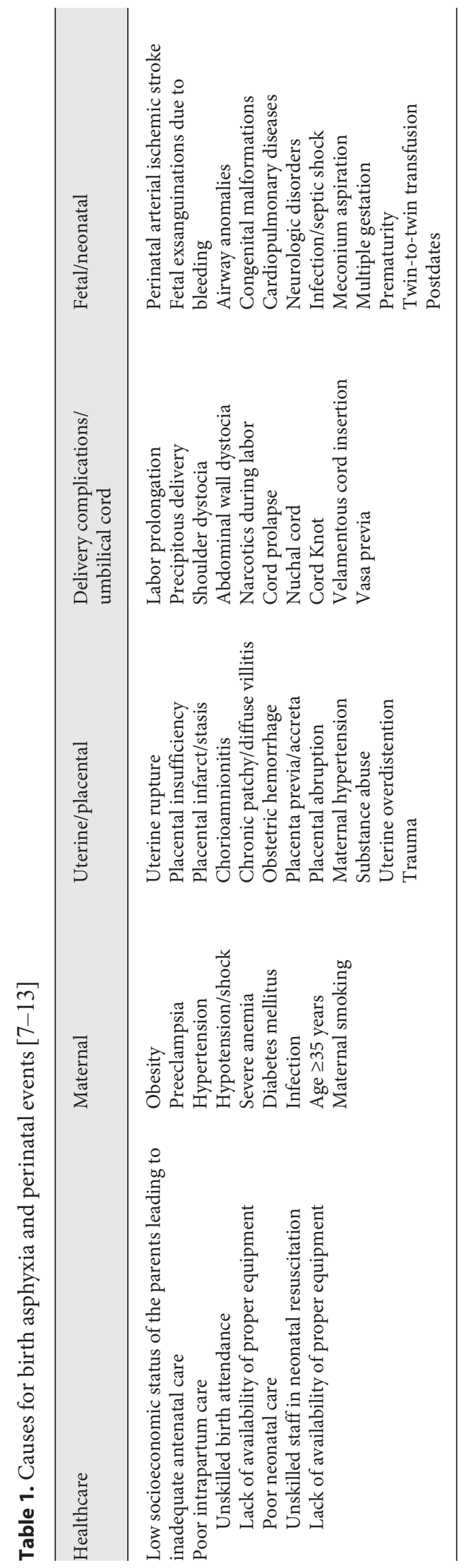

tilation (PPV) a decade ago, a 30\% reduction in mortality was demonstrated [14]. However, still a substantial number of deaths may be preventable by improvements in neonatal resuscitation. Prompt resuscitative measures are needed to prevent cerebral injury by avoiding further hypoxia and ischemia and reversing respiratory and metabolic acidosis [13, 15-17]. The aim of this review is to give an overview of DR management in asphyxiated term and near-term newborn infants.

\section{Umbilical Cord Management}

Neonatal resuscitation guidelines state that infants, who require resuscitation measures, should have immediate cord clamping [18]. The European Resuscitation Council Guidelines state that where delayed cord clamping is not possible, cord milking should be considered in infants $>28$ weeks' gestation [19]. However, the optimal umbilical cord management strategy, which improves outcomes for asphyxiated term newborns, remains unknown [20]. A recent systematic review compared various umbilical cord management strategies including a total of 9,159 women and infant pairs in late preterm $\left(34^{+0}\right.$ $36^{+6}$ weeks' gestational age) and term ( $\geq 37$ weeks' gestational age) infants. Unfortunately, none of the included trials reported on the primary outcome of survival without moderate to severe neurodevelopmental impairment in early childhood. By randomizing vigorous term infants to immediate cord clamping versus umbilical cord milking or to delayed versus immediate umbilical cord clamping, no significant differences in neonatal outcomes (including Apgar scores, need for resuscitation, or admissions to the neonatal intensive care unit) were found [21]. Recently, updated $\mathrm{SpO}_{2}$ and $\mathrm{HR}$ percentiles in term infants with delayed cord clamping were published [22]. They reported on higher $\mathrm{SpO}_{2}$ and $\mathrm{HR}$ values and earlier stabilization compared to term infants with immediate cord clamping [22].

\section{Umbilical Cord Milking}

Erickson-Owens et al. [23] randomized 24 vigorous term infants to immediate cord clamping or umbilical cord milking and reported comparable Apgar scores and need for resuscitation, with no admissions. While studies suggest that umbilical cord milking is an alternative to immediate cord clamping in vigorous infants, there is a lack of data in nonvigorous infants. A retrospective analysis of 157 late preterm and term infants (35-42 weeks) with abnormal umbilical cord blood gases (cord arterial or ve- 
nous $\mathrm{pH}$ of $\leq 7.1$ or base deficit $<-12 \mathrm{mmol} / \mathrm{L}$ ) reported fewer infants needing resuscitation (38 vs. 56\%, $p=0.07$ ) and ongoing respiratory support (19 vs. $31 \%$, $p=0.16$ ) with umbilical cord milking compared to immediate cord clamping [24]. Girish et al. [25] compared umbilical cord milking with immediate cord clamping in 101 depressed term neonates at birth in a quasirandomized (alternating months) trial and reported no differences in resuscitation delay, resuscitation efforts, and short-term outcomes. There is a multicenter trial examining immediate cord clamping with umbilical cord milking in nonvigorous newborn infants, $35^{+0}-41^{+6}$ weeks' gestation, currently ongoing (ClinicalTrials.gov NCT03631940).

\section{Physiological-Based Cord Clamping}

During physiological-based cord clamping, the infants remain attached to the umbilical cord until gas exchange/ lung aeration has occurred, and this might be an alternative to delayed cord clamping and umbilical cord milking; however, there are currently limited data available. Studies using asphyxiated near-term lambs reported that resuscitation with intact umbilical cord (i) markedly improved cardiovascular function by increasing venous return to right atrium and pulmonary blood flow, (ii) mitigated rebound hypertension, and (iii) reduced cerebral vascular leakage compared with immediate or delayed cord clamping [20, 26, 27]. A recent randomized controlled trial in 231 nonbreathing newborn infants compared resuscitation with intact umbilical cord or immediate cord clamping [28]. Peripheral arterial oxygen saturation $\left(\mathrm{SpO}_{2}\right)$ was significantly higher in the resuscitation with intact umbilical cord group with a mean (SD) of 90.4 (8.1) versus 85.4 (2.7)\% in the immediate cord clamping group. Apgar scores were higher as well in the intact umbilical cord group compared to immediate cord clamping, while heart rate (HR) was lower in the intact umbilical cord group at 1 and 5 min compared to immediate cord clamping [28]. Whether physiological-based cord clamping or resuscitation on the intact umbilical cord will improve the outcome of asphyxiated newborn infants remains unclear.

\section{Heart Rate Assessment}

Current neonatal resuscitation guidelines recommend to asses HR immediately after birth using pulse oximetry or electrocardiography (ECG) for ongoing monitoring $[18,29]$. Clinical studies reported that inter- and intraobserver variability with auscultation and palpation un-

Delivery Room Management of

Asphyxiated Infants derestimates HR about 21 and 14/min, respectively [3032]. Furthermore, neither palpation nor auscultation can provide continuous HR assessment during resuscitation. Hence, continuous, objective, and precise measures are required. Both pulse oximetry and ECG fulfill these criteria with very good accuracy [33]. Due to the delay in obtaining a signal with the pulse oximeter, the ECG provides a more accurate $\mathrm{HR}$ in the first 3 min after birth [18]. In 2015, the neonatal resuscitation guidelines recommended routine use of ECG for continuous monitoring of HR during DR resuscitation [34]. The American Heart Association/Neonatal Resuscitation Program (AHA/NRP), however, recommends that "auscultation of the precordium remains the preferred physical examination method for the initial assessment of the heart rate. Pulse oximetry and ECG remain important adjuncts to provide continuous heart rate assessment in babies needing resuscitation" [2].

\section{Pulseless Electrical Activity}

The practice change following the ILCOR recommendation of applying ECG primarily to detect HR led to several case reports of pulseless electrical activity in the DR $[35,36]$. Pulseless electrical activity is defined as the presence of electrical activity without any associated mechanical activity $[35,36]$. Similar animal studies reported pulseless electrical activity in $~ 50 \%$ of asphyxiated neonatal piglets [35, 37-39]. Pulseless electrical activity is caused by hypoxia, hyper-/hypokalemia, hypovolemia, hypothermia, hydrogen ions (acidosis), tension pneumothorax, cardiac tamponade, thrombosis (coronary and pulmonary), and toxins [40]. These reports raise concerns about the use of ECG in the DR, and therefore healthcare providers should be aware of the potential pitfalls with ECG during neonatal resuscitation [35]. A recent case series stated that if a HR is displayed on the ECG but the infant is unresponsive, pulseless electrical activity should be suspected and chest compressions should be started [35]. We suggest to combine auscultation, palpation, pulse oximetry, and ECG in asphyxiated newborn infants, which might be more reliable compared to ECG or pulse oximetry alone $[39,41]$.

\section{Respiratory Support}

In the first 1-2 min after birth, $\sim 60$ and $17 \%$ of spontaneously breathing term infants have a $\mathrm{HR}<100$ and $<60 / \mathrm{min}$, respectively [42]. At $3 \mathrm{~min}$ after birth, $7 \%$ of these spontaneously breathing term infants still have a 
$\mathrm{HR}<100 / \mathrm{min}$ [42]. In spontaneously breathing term infants, it took $1-10$ breaths to the first expired $\mathrm{CO}_{2}\left(\mathrm{ECO}_{2}\right)$ and 21-258 s until peak $\mathrm{CO}_{2}$, suggesting complete lung aeration $[43,44]$. Similarly, during PPV, ECO $\mathrm{EC}_{2}$ levels are closely related to lung volumes at end inflation, and $\mathrm{ECO}_{2}$ is first detected when $\sim 7 \%$ of the distal lung regions are aerated, and $\mathrm{ECO}_{2}$ levels increase $\sim 30 \mathrm{~s}$ before $\mathrm{HR}$ increased $>100 / \min [45,46]$.

While these data suggest that an increase in HR might be delayed despite adequate ventilation, the Neonatal Resuscitation Program textbook states that once PPV is started, an increase in HR should be observed within $15 \mathrm{~s}$ [47]. However, in severe bradycardic asphyxiated newborn piglets, HR increased only in $50 \%$ of piglets after 30 s of adequate PPV [48]. Saugstad et al. [49] reported that the HR of asphyxiated newborn infants was mean (SD) 93 (33) and 113 (30) at 60 and $90 \mathrm{~s}$ after birth, respectively. In another study, Saugstad et al. [14] reported that the HR was $\leq 100 / \mathrm{min}$ in approximately $2 / 3$ and $1 / 6$ of depressed newborn infants at 1 and $3 \mathrm{~min}$ after birth, respectively. Furthermore, a slow or no increase in HR in the first 3 min of life seemed to represent a poor prognostic sign, giving a 9-fold risk for death within a week [14].

\section{Mask Ventilation}

The current neonatal resuscitation guidelines recommend mask ventilation using an appropriate face mask connected to a manual ventilation device $[1,2]$. The most commonly used devices to provide PPV in the DR are a self-inflating bag and T-piece resuscitator [50, 51]. A recent systematic review included 3 randomized trials and 1 observational study and reported no significant differences in survival at discharge, air leak, or short- and longterm outcomes [52]. However, mask ventilation with a $\mathrm{T}$-piece resuscitator might result in fewer intubations in the DR and higher rates of survival to discharge [52].

During ventilation, an initial peak inspiratory pressure (PIP) of $30 \mathrm{~cm} \mathrm{H}_{2} \mathrm{O}$ in term newborn infants should be used $[18,19,53]$. However, the optimum pressure, inflation time, and gas flow required to establish an effective functional residual capacity in depressed newborn infants is unknown. Dawson et al. [50] reported that PIP is a poor proxy for tidal volume delivery and that the PIP must be adjusted during resuscitation as compliance and resistance of the lung is changing rapidly. However, a prompt increase of HR above 100/min can be an important sign of adequate tidal volume generated by the chosen PIP during resuscitation.

The 2-point top hold and the OK rim hold (thumb and index finger form a C-shape) are the most adequate face mask techniques for placing and holding a face mask and minimizing mask leak during PPV [54]. However, several DR studies reported that mask leak and airway obstruction are common during bag and mask PPV in particular in preterm infants $[55,56]$. Mask leak and obstruction often remain unrecognized and might delay lung aeration, hence effective gas exchange and increase in HR. In a very recent meta-analysis comparing face mask with nasal cannulae for noninvasive PPV in the DR reported a nonsignificant reduced risk for chest compressions ( 3 studies, RR $0.37,95 \%$ CI: $\left.0.10-1.33, p=0.13, I^{2}=28 \%\right)$ and a nonsignificant reduction in DR intubation rates (5 studies, $\mathrm{RR}$ 0.63 , 95\% CI: $0.39-1.02, p=0.06, I^{2}=52 \%$ ) when using nasal cannulae, suggesting to consider the use of nasal cannulae as an alternative to face mask PPV [57].

Intrauterine hypoxia suppresses fetal breathing movements and causes apnea and glottis closure (=airway obstruction) after birth [58]. In preterm rabbits, Crawshaw et al. [58] reported that the glottis only opens during spontaneous breathing movements while it remains closed during apnea, which might result in ineffective PPV [59]. Glottis closure might also be present in term infants; however, this has not been investigated yet.

\section{MR. SOPA}

Current neonatal resuscitation guidelines recommend a face mask in combination with a manual ventilation device to provide respiratory support after birth $[18,19]$. A tight seal between mask and face and appropriate positioning of the infant's upper airway are important for effective mask ventilation. When infants do not respond to initial inflations, the neonatal resuscitation program (NRP, Houston, TX, USA) and the neonatal life support group (NLS, United Kingdom) suggest a structured approach for escalation of care. MR. SOPA is thought to be used as an acronym for $\mathbf{M}$ (mask adjustment), $\mathbf{R}$ (reposition airway), $\mathbf{S}$ (suction mouth and nose), $\mathbf{O}$ (open mouth), $\mathbf{P}$ (pressure increase), and $\mathbf{A}$ (alternate airway) as a laryngeal mask airway (LMA) or endotracheal tube.

\section{Sustained Inflation}

The current European neonatal resuscitation guidelines recommend 5 consecutive 2 - to 3 -s sustained inflations to initiate PPV [19]. However, there is no clinical evidence that these 5 initial sustained inflations will support lung aeration. Studies in near-term intrauterine asphyxiated lambs demonstrated that a single sustained inflation of $30 \mathrm{~s}$ improves the speed of circulatory recovery, carotid blood flow, and cerebral oxygen delivery, and further cardiac contractility increases more rapidly com- 
pared to PPV or 5 consecutive 3-s sustained inflations $[60,61]$. However, cerebral plasma protein extravasation was increased after a single 30 -s sustained inflation, indicating a greater disruption in the blood-brain barrier, which might exacerbate brain injury in asphyxiated newborns [61]. These data suggest that one 30-s sustained inflation might improve lung aeration compared to 5 consecutive 3-s sustained inflations. The 2020 ILCOR neonatal resuscitation guidelines state that for term or late preterm infants who receive PPV for bradycardia or ineffective respirations at birth, it is not possible to recommend any specific duration for initial inflations due to the very low confidence in effect estimates [1].

\section{Oropharyngeal Airway}

The oropharyngeal airway was designed to hold the tongue away from the back of the pharynx, thus providing a clear channel/airway for respired gases. The European Neonatal Resuscitation guidelines recommend an oropharyngeal airway during their structured approach for escalation of care [19]. Kamlin et al. [62] randomized 137 infants $<34$ weeks' gestational age to either mask PPV alone or in combination with an appropriately sized oropharyngeal airway. Overall, obstructed inflations and partial obstruction were more frequently observed in infants stabilized with an oropharyngeal airway ( 81 vs. $64 \%$, $p=0.03$, and 70 vs. $54 \%, p=0.04$ ), respectively [62]. The trial included infants $<34$ weeks' gestation only, which makes translation to term babies difficult. However, healthcare providers should be aware that an oropharyngeal airway might increase airway obstruction during mask ventilation.

\section{Laryngeal Mask Airway}

The current neonatal resuscitation guidelines recommend an LMA as an alternative to tracheal intubation during resuscitation of newborn infants $>34$ weeks' gestation $[18,19]$. A recent Cochrane review with 794 newborn infants reported that PPV with an LMA resulted in less need for endotracheal intubation and shorter ventilation time compared to mask PPV (RR [95\% CI]: 0.24 [0.120.47], $I^{2}=34 \%$, and mean difference [95\% CI]: $-18.0 \mathrm{~s}$ $[-24.35$ to $\left.-13.44 \mathrm{~s}], I^{2}=95 \%\right)$, respectively [63]. Insertion time or failure to correctly place either an LMA or an endotracheal tube was similar [63]. The current evidence suggests that an LMA might be an adequate alternative during resuscitation of a severe asphyxiated term infant. Pejovic et al. [64] compared LMA and face mask during neonatal resuscitation in a low-resource setting and demonstrated that the total ventilation time and the mean

Delivery Room Management of

Asphyxiated Infants time to spontaneous breathing were shorter in newborn infants who were initially resuscitated with LMA. It was suggested that this approach could be very useful especially in DR settings with resuscitation teams without adequate skills in tracheal intubation and/or in low- and middle-resource settings [65]. Pejovic et al. [66] reported that an LMA is safe in the hands of midwives but is not superior over a face mask with respect to the composite of early neonatal death or moderate-to-severe hypoxicischemic encephalopathy (HIE) (adjusted analysis for LMA vs. face mask: RR, 95\% CI: 1.16 [0.90-1.51], $p=$ 0.26 ) in low-resource settings.

\section{Oxygen}

\section{Oxygen during Respiratory Support}

Already a decade ago, studies demonstrated that asphyxiated term infants resuscitated with room air gave their first cry earlier and attained a sustained pattern of spontaneous respiration more rapidly compared to those with $100 \%$ oxygen resuscitation $[67,68]$. Vento et al. [69, $70]$ showed that using pure oxygen for neonatal resuscitation increases oxidative stress and causes more damage to organs including the heart and kidneys in severely asphyctic term neonates. For term and near-term newly born infants, the current neonatal resuscitation guidelines recommend $21 \%$ oxygen initially during respiratory support and $100 \%$ oxygen when chest compressions are started $[18,19$, $71,72]$. Supplemental oxygen should then be titrated according to preductal oxygen saturation targets $[18,19,72]$. A systematic review and meta-analysis including 5 quasirandomized controlled trials and 1,302 newborn infants (median 38 weeks' gestation and most of them moderately asphyxiated) reported that outcomes as time to first breath $>3$, 5-min Apgar score $<7$, and survival were better for those resuscitated with room air rather than $100 \%$ oxygen [73]. Further, 1 death would be prevented for every 20 newborn infants resuscitated with air rather than $100 \%$ oxygen [73]. Hence, room air instead of pure oxygen resuscitation may prevent 200,000 deaths, in addition to 300,000 fresh still births (out of approximately 1 million) who may be rescued by room air ventilation [74].

\section{Chest Compressions}

Current neonatal resuscitation guidelines state that if the HR remains $<60 / \mathrm{min}$ despite adequate ventilation, chest compression should be started $[19,29]$. Chest com- 
pression should be delivered using a (i) coordinated 3:1 compression:ventilation $(\mathrm{C}: \mathrm{V})$ ratio, (ii) at the lower third of the sternum, (iii) a depth of $\sim 1 / 3$ of the anteriorposterior diameter of the chest, (iv) using the 2-thumb encircling technique, and (v) allowing full chest recoil relaxation. However, these recommendations are based on extrapolations from mathematic modeling, animal data, and pediatric and adult studies as there is a lack of neonatal human data.

\section{Chest Compression:Ventilation Ratio}

Rationales for using 3:1 C:V include (i) a higher physiological HR of $120-160 / \mathrm{min}$ and (ii) breathing rates of $40-60 / \mathrm{min}$ in newborn infants compared to adults. Several studies compared different C:V ratios $(2: 1,3: 1,4: 1$, 9:3, and 15:2) in asphyxiated newborn piglets showing that time to return of spontaneous circulation (ROSC) was similar, independently of C:V ratio [75-77]. Schmölzer et al. [78] investigated the approach of chest compressions with nonsynchronized ventilation and reported that tidal volume, time to ROSC, survival, and hemodynamic recovery were similar compared to $3: 1 \mathrm{C}: \mathrm{V}$ in asphyxiated neonatal piglets.

\section{Chest Compression Rate}

A mathematical model suggests that the chest compression rate should be $180 / \mathrm{min}$ for term infants [79] However, this might not be feasible due to methodological limitations and rescuers' increased fatigue with higher chest compression rate. Furthermore, animal studies compared various chest compression rates and reported no difference in time to ROSC or survival $[80,81]$. Neither different rates of chest compression superimposed by sustained inflations (90 vs. 120/min) nor different rates of chest compression with asynchronized ventilation (90, 100 , and $120 / \mathrm{min}$ ) showed a benefit regarding time to ROSC and survival in neonatal asphyxiated piglets, although the hemodynamic recovery, cerebral inflammatory, and brain injury markers were improved during chest compression with asynchronized ventilation with a rate of $120 / \mathrm{min}$ compared to 90 or $100 / \mathrm{min}[80,81]$.

\section{Depth of Chest Compression}

The recommendation regarding chest compression depth is based on extrapolation from CT scans in 54 neonates, which showed that a $1 / 3$ anterior-posterior depth would result in a superior ejection fraction compared to $1 / 4$ or $1 / 2$ AP depth [82]. The main difficulty for resuscitators is the inability to assess the chest compression depth during chest compression. A too shallow anterior- posterior diameter could result in inadequate cardiac output, and a too high anterior-posterior diameter could cause overcompression resulting in rib fractures, cardiac contusion, and thoracic injuries.

\section{Chest Compression Technique}

Several manikin studies demonstrated that the 2-thumb encircling technique achieved (i) higher proportion of correct placements of the fingers/thumbs, (ii) greater mean (SD) depth (27.2 [5.7] vs. 22.1 [4.6] mm; $p=0.0008)$, and (iii) less mean (SD) depth variability (6.7 [3.2]\% vs. $9.0[2.8] \% ; p=0.002)$ compared to the 2 -finger technique during chest compression $[83,84]$. There has been one animal study comparing the 2 -thumb technique and the 2-finger technique in 9.4 (SD 0.8) kg infant swine, which reported significantly higher systolic, diastolic, and mean arterial blood pressure and coronary perfusion pressure [85]. More recently, newer techniques of how to position the thumbs and fingers during chest compression have been described in manikin studies; however, further studies investigating the optimal thumbs and fingers position during chest compression are urgently needed to improve the newborn infants' short- and longterm outcome.

\section{Oxygen during Chest Compression}

Current neonatal resuscitation guidelines recommend increasing oxygen to $100 \%$ when chest compression is started [18]; however, the optimal/most effective oxygen concentration during chest compression remains unknown/controversial. While there are no human data, animal studies reported that $21 \% \mathrm{O}_{2}$ results in not significantly different time to ROSC, survival, and neurologic outcomes compared to $100 \% \mathrm{O}_{2}$ [18]. A recent meta-analysis of animal studies reported that the pooled analysis showed no significant difference in mortality rates for animals resuscitated with air versus $100 \% \mathrm{O}_{2}$ (risk ratio $1.04[0.35,3.08], I^{2}=0 \%, p=0.94$ ) [86]. ROSC was also similar between groups with a mean difference of -3.8 ( -29.7 to 22$)$ s, $I^{2}=0 \%, p=0.77$ [86]. Most recently, 2 further studies compared $21 \%$ with $100 \% \mathrm{O}_{2}$ using a neonatal asphyxia piglet model. No difference in time to ROSC, survival, oxidative stress, and inflammation markers was found $[87,88]$. While these studies suggest that $21 \%$ is not different to $100 \% \mathrm{O}_{2}$, no clinical studies have been reported and are urgently needed.

\section{Chest Compression during Sustained Inflation}

An alternative chest compression method is chest compression superimposed during sustained inflation 
$(\mathrm{CC}+\mathrm{SI})$, which (i) reduced time to ROSC and (ii) improved survival, (iii) improved hemodynamics (carotid artery blood flow and pulmonary artery blood flow), and (iv) resulted in passive ventilation during chest compression and thereby increasing minute ventilation compared with 3:1 C:V ratio in asphyxiated newborn piglets [89]. In a small human pilot trial in preterm infants $<32$ weeks, the time to ROSC was significantly shorter in the CC + SI group compared to the $3: 1 \mathrm{C:V}$ group with mean (SD) 31 (9) versus 138 (72) s [90]. The SURV1VE trial currently compares whether CC + SI with 3:1 C:V improves shortand long-term outcomes in preterm $>28$ weeks and term newborns (ClinicalTrials.Gov Trial NCT02858583) [91].

\section{Vascular Access}

Current neonatal resuscitation guidelines recommend to establish an intravenous access as soon as possible to administer epinephrine (adrenaline), fluids, or blood if needed $[18,19,29]$. The most common approach is to place an umbilical venous catheter $\sim 5 \mathrm{~cm}$ into the umbilical vein $[18,19,29]$. This procedure could take several minutes, especially when the equipment is not prepared or performed by an inexperienced healthcare provider [92, 93]. Alternatively, a peripheral intravenous access or an intraosseous (IO) access could be established $[1,19,94,95]$. Simulation studies reported that IO insertion was faster compared to umbilical venous catheter insertion [96]. Inserting a needle into the (tibial) bone allows a quick drug administration to the IO blood vessel system even during compromised circulation and shock. Cadaveric studies reported that IO needle position (i.e., humerus and proximal tibia) is feasible with both a semiautomatic battery-driven drill and manually inserted needles $[97,98]$. A recent systematic review identified observational and simulation studies but no randomized trials [96]. A total of $46 \mathrm{IO}$ needle insertions in 41 neonates (mostly inserted in the proximal tibia), with a complication rate of $13-31 \%$ (e.g., malpositioned needles, displaced needles, extravasation, local infection, osteomyelitis, fracture, compartment syndrome, limb ischemia, and fat or air emboli), was described [96]. More recently, Mileder et al. [99] reported 12 additional cases of IO needle insertions using a battery-driven drill in newborn infants with a $50 \%$ success rate for the first and second attempt. No long-term complications were reported; however, minor short-term complications (i.e., paravasation and local soft tissue infection) in 33\% of successful IO insertions were observed [99]. The 2020 ILCOR neonatal

Delivery Room Management of

Asphyxiated Infants resuscitation guidelines stated that if umbilical venous access is not feasible, the IO route is a reasonable alternative for vascular access during newborn resuscitation. However, adverse effects including tibial fractures and extravasation of fluid and medications resulting in compartment syndrome and amputation are emphasized [1].

Most recently, direct puncture of the umbilical vein through Wharton's jelly using a 24-gauge cannula as an alternative method for drug administration was described [100]. A case series of 10 cases $(n=4$ epinephrine during $\mathrm{CPR}$ and $n=6$ premedication of intubation) was described, and the whole procedure from puncture to drug administration took 15-20 s. There is a lack of data, and clinical trials are urgently needed.

\section{Epinephrine (Adrenaline)}

Current neonatal resuscitation guidelines recommend 1:10,000 epinephrine given intravenously at a dose of $0.01-0.03 \mathrm{mg} / \mathrm{kg}$ [1]. Alternatively, endotracheal administration at a dosage of $0.05-0.1 \mathrm{mg} / \mathrm{kg}$ might be considered while intravenous access is established [29]. Epinephrine acts on $\alpha$ - and $\beta$-receptors resulting in (i) increased coronary artery perfusion pressure via peripheral vasoconstriction, (ii) improved blood flow to the myocardium, and (iii) restored depleted energy substrates, thus improving myocardial contractility and viability. However, epinephrine also increases myocardial oxygen demand and respiratory and metabolic acidosis, a common occurrence during neonatal asphyxia [101]. A recent systematic review included 117 term and preterm infants receiving epinephrine in the DR and reported similar outcomes for death at hospital discharge (RR [95\% CI] 1.03 [0.62-1.71]) or failure to achieve ROSC, time to ROSC, or proportion receiving additional epinephrine between intravenous and endotracheal epinephrine [102]. These data suggest that endotracheal and intravenous epinephrine results in similar survival and other outcomes. However, in animal studies, researchers continue to suggest benefit of intravenous administration using currently recommended doses. Human clinical trials are urgently needed.

\section{Nonvigorous Infants and Meconium-Stained Amniotic Fluid}

Meconium-stained amniotic fluid occurs in up to $15 \%$ of deliveries, $10-20 \%$ of these infants are born nonvigorous $[103,104]$, and $5-10 \%$ of these infants will develop meconium aspiration syndrome (MAS) $[105,106]$. In 
2015, the neonatal resuscitation guidelines changed their recommendation to emphasis not routinely suction in nonvigorous meconium-stained amniotic fluid infants [71]. Several studies compared outcomes before and after guideline changes and reported less neonatal intensive care unit admissions, less infants receiving tracheal suctioning, and no increase in severity of MAS or severe respiratory distress or other important neonatal outcomes [107-109]. Noteworthy, Kalra et al. [108] reported a similar prevalence of HIE and pneumothorax while Edwards et al. [107] reported an increased incidence. While Chiruvolu et al. [103] reported that a significantly higher proportion of nonvigorous infants with meconium-stained amniotic fluid were admitted with respiratory distress and respiratory support.

Recent meta-analyses included 581 nonvigorous infants with meconium-stained amniotic fluid and reported no difference in neonatal mortality, incidence of MAS and HIE, need for DR interventions, respiratory support, or hospital stay between suctioning below the vocal cord and no suctioning $[110,111]$. These data suggest that there is no clear evidence of benefits of initial endotracheal intubation and tracheal suction in meconiumstained amniotic fluid; however, if there is airway obstruction due to thick viscous, meconium suctioning is often a clinical decision [17].

\section{Temperature Management}

Current neonatal resuscitation guidelines recommend maintaining body temperature of nonasphyxiated newborn infants between 36.5 and $37.5^{\circ} \mathrm{C}$ after delivery through admission and stabilization [19, 29, 72]. In infants with HIE, therapeutic hypothermia should be initiated within the first $6 \mathrm{~h}$ after birth [112]. Both active and passive cooling are feasible and safe to achieve a target body temperature of $33-34^{\circ} \mathrm{C}$ in asphyxiated term born infants $>36$ weeks' gestational age [113]. Asphyxiated newborn infants have impaired thermoregulation due to reduced oxygen consumption and energy production, a high surface area, and a wet and thin skin and lose temperature at a higher rate than nonasphyxiated infants. Infants with potentially higher degree of brain injury cool faster, as their natural protective mechanisms are inhibited [114, 115]. Initiating cooling sooner might prevent worsening of brain tissue injury; therefore, passive cooling should be started after the initial stabilization or during neonatal transport [116]. Especially in community hospitals or remote/rural areas, passive cooling is a good alternative to initiate cooling as early as possible. Several studies reported that infants passively cooled during transport achieved target temperature significantly faster compared to infants who were not passively cooled [117, 118]. However, passive cooling during transport resulted in $\sim 1 / 3$ of infants in overcooling, in particular in infants with mostly severe HIE $[118,119]$. Overcooling can be avoided by using a servo-regulated cooling device (cooling blanket and rectal/esophageal temperature probe) during neonatal transport. A randomized controlled trial demonstrated that the mean time to reach target temperature with using a servo-regulated cooling device compared to either passively and/or actively (ice or gel packs) cooling was $44 \mathrm{~min}$ [120]. Thus, if servo-regulated cooling is initiated soon after arrival of the transport team in the birth hospital, many infants will achieve target temperature prior to departure from the birth hospital [120]. However, there is neither evidence nor clear recommendation how to process with body temperature of asphyxiated newborn infants with suspected HIE during neonatal resuscitation. The 2020 ILCOR neonatal resuscitation guidelines suggest treatment should be consistent with the protocols used in the randomized clinical trials [1]. This includes active cooling with ice packs [121]; however, caution is required when using this approach as it increases the risk for overcooling.

\section{Neonatal Resuscitation in Resource-Limited versus Resource-Replete Environments}

Of the approximately 2.6 million newborn infants who die annually, 98\% occur in resource-limited environments, and $50-70 \%$ of neonatal deaths occur on the first day after birth [122]. Neonatal mortality is about 50-55 times higher in low- and middle-income countries compared to high-income countries due to mother's health (i.e., nutritional and infection status), limited resources, and lack of trained birth attendants or failure to provide adequate basic neonatal resuscitation at birth [123, 124].

Birth asphyxia is defined differentially in resourcelimited and resource-replete environments [125]. However, in resource-limited environments, it is usually defined as a failure to initiate or sustain spontaneous breathing at birth and in some circumstances includes a 1-min Apgar score $<7$; in resource-replete environments, it is a biochemical definition ( $\mathrm{pH}<7.00$ and base deficit $\leq-12$ $\mathrm{mmol} / \mathrm{L}$ ), related to impaired gas exchange (leading to organ failure including HIE), due to interruption of placental blood flow, with progressive hypoxemia, hyper- 
Table 2. Neonatal resuscitation of asphyxiated term infants in resource-limited versus resource-replete environments

\begin{tabular}{|c|c|c|}
\hline & Limited resources & Replete resources \\
\hline Cord clamping & Delayed cord clamping [120] & $\begin{array}{l}\text { Immediate cord clamping to initiate resuscitation } \\
\text { measures [18] }\end{array}$ \\
\hline Basic steps of neonatal resuscitation & $\begin{array}{l}\text { Dry thoroughly, keep warm, clear airway if needed, } \\
\text { stimulate [120] }\end{array}$ & $\begin{array}{l}\text { Dry thoroughly, keep warm, clear airway if needed, } \\
\text { stimulate [18] }\end{array}$ \\
\hline HR assessment & $\begin{array}{l}\text { Auscultation if a stethoscope is available, if not cord } \\
\text { palpation [121] }\end{array}$ & $\begin{array}{l}\text { Pulse oximetry or ECG [18], stethoscope before PO, or } \\
\text { ECG signals [2] }\end{array}$ \\
\hline Meconium-stained amniotic fluid & $\begin{array}{l}\text { Drying and stimulation before suctioning, if needed } \\
\text { [120] }\end{array}$ & $\begin{array}{l}\text { Emphasize initiating ventilation in nonvigorous } \\
\text { infants, suctioning if airways are obstructed [19] }\end{array}$ \\
\hline Indication to provide respiratory support & Apneic infants [120] & Apneic infants or/and HR $<100$ beats/min [18] \\
\hline Respiratory support & $\begin{array}{l}\text { Early continuous bag-mask ventilation [120] or using } \\
\text { an LMA as alternative [63] }\end{array}$ & $\begin{array}{l}\text { Mask ventilation using a manual ventilation device and } \\
\text { escalate (intubation) if needed [18] }\end{array}$ \\
\hline Supplemental oxygen & Room air [122] & $\begin{array}{l}\text { Start with room air and titrate supplemental oxygen } \\
\text { according to preductal oxygen saturation targets [18] }\end{array}$ \\
\hline Cardiocirculatory support & No CC, no drugs such as epinephrine [114] & $\begin{array}{l}\text { If the HR remains }<60 / \text { min despite adequate } \\
\text { ventilation, CC should be started and epinephrine } \\
\text { administrated [18] }\end{array}$ \\
\hline Temperature management & $\begin{array}{l}\text { Swaddle in clean clothes or if available use clean } \\
\text { food-grade plastic bag and swaddle }[18,120]\end{array}$ & $\begin{array}{l}\text { No clear recommendations, ILCOR suggest active } \\
\text { cooling consider passive cooling [104] }\end{array}$ \\
\hline Therapeutic hypothermia & $\begin{array}{l}\text { Should only be considered, initiated, and conducted } \\
\text { under clearly defined protocols with treatment } \\
\text { in neonatal care facilities with the capabilities for } \\
\text { multidisciplinary care [18] }\end{array}$ & $\begin{array}{l}\text { Should be initiated according to strict criteria within } \\
6 \mathrm{~h} \text { after birth targeting a body temperature of } 33-34^{\circ} \mathrm{C} \\
{[18]}\end{array}$ \\
\hline Discontinuation of resuscitation & $\begin{array}{l}\text { Stop assisted ventilation in babies with no } \\
\text { spontaneous breathing despite presence of HR or } \\
\text { Apgar score of } 1-3 \text { at } 20 \text { min or more [18] }\end{array}$ & $\begin{array}{l}\text { Can be stopped if the neonate does not respond to } \\
\text { continuous and adequate interventions around } 20 \text { min } \\
\text { after birth. Consider individual decision-making [1] }\end{array}$ \\
\hline $\begin{array}{l}\text { Training strategies for healthcare } \\
\text { providers }\end{array}$ & $\begin{array}{l}\text { Low-dose, high-frequency practice, participation on } \\
\text { programs such as "helping babies breathe" }[120,123]\end{array}$ & $\begin{array}{l}\text { Recurrent simulation and video-taping training, } \\
\text { considered more frequently than once per year }[18,19]\end{array}$ \\
\hline
\end{tabular}

capnia, and acidosis analyzing cord umbilical arterial blood after delivery of the newborn $[125,126]$.

To improve the outcome of newborn infants born in limited resource settings, the Global Implementation Task Force of the American Academy of Pediatrics developed together with other partners the "Helping Babies Breathe" training in 2010, a simulation-based training method designed to train healthcare providers in limited resource settings in neonatal resuscitation and care [127]. Implementing this training and resuscitation method is a simple and low-cost intervention that reduces intrapartum-related stillbirths and early neonatal mortality [127]. This systematic review showed moderate evidence for a decrease in intrapartum-related stillbirth and 1-day neonatal mortality rate after implementing the "Helping Babies Breathe" training and resuscitation method [127].
Table 2 gives an overview about the differences of recommendations regarding neonatal resuscitation in limited versus replete resource settings.

\section{Discontinuation of Resuscitation}

The current neonatal resuscitation guidelines [1] state that a reasonable timeframe to consider before ending resuscitation "is around" 20 min after birth. Recently, the Neonatal Life Support Task Force reported that $40 \%$ of infants with ongoing need for CPR at $10 \mathrm{~min}$ after birth survived with $11 \%$ surviving without moderate or severe impairment [128]. However, all included studies had high risk of bias, considering contextual factors such as gestational age, presence of congenital anomalies, or adequacy 
of resuscitative interventions performed. These data suggest that a uniform time interval or duration of CPR after birth will not be applicable [128]. The most recent guidelines suggesting to end resuscitation "around $20 \mathrm{~min}$ after birth" is a good approach for the patient, the parents, and the providers $[1,41]$.

\section{Conclusion}

DR management must be steadily evaluated, investigated, and trained to improve resuscitation of asphyxiated newborn infants. Current neonatal resuscitation guidelines often focus on preterm infants, not recommending different approaches for asphyxiated term born infants. Hence, strong efforts must be undertaken to perform studies of high quality in the DR to further improve neonatal resuscitation and outcome of one of the sickest groups of newborn infants.

\section{Acknowledgement}

The article is accompanied by a lecture "Management of asphyxiated term infant," which was given as a webinar for the UENPS (Union of European Neonatal and Perinatal Societies) https://vimeo.com/423212885/d90783306b.

\section{Conflict of Interest Statement}

The authors have no conflicts of interest to declare.

\section{Funding Sources}

The authors did not receive any funding.

\section{Author Contributions}

Conception and design: M.B., G.L., O.D.S., and G.M.S. Analysis and interpretation of the data: M.B., G.L., O.D.S., and G.M.S. Drafting of the article: M.B., G.L., O.D.S., and G.M.S. Critical revision of the article for important intellectual content: M.B., G.L., O.D.S., and G.M.S. Final approval of the article: M.B., G.L., O.D.S., and G.M.S.

\section{References}

1 Wyckoff MH, Wyllie J, Aziz K, de Almeida MF, Fabres JW, Fawke J, et al. Neonatal life support 2020 International Consensus on Cardiopulmonary Resuscitation and emergency cardiovascular care science with treatment recommendations. Resuscitation. 2020 Nov;156(16 Suppl 2):A156-87.

2 Aziz K, Lee HC, Escobedo MB, Hoover AV, Kamath-Rayne BD, Kapadia VS, et al. Part 5: neonatal resuscitation: 2020 American Heart Association guidelines for cardiopulmonary resuscitation and emergency cardiovascular care. Circulation. 2020 Oct 20;142(16_Suppl 1 2):S524-50.

3 Barber CA, Wyckoff MH. Use and efficacy of endotracheal versus intravenous epinephrine during neonatal cardiopulmonary resuscitation in the delivery room. Pediatrics. 2006 Sep 1;118(3):1028-34.

4 Harrington DJ, Redman CW, Moulden M, Greenwood CE. The long-term outcome in surviving infants with Apgar zero at $10 \mathrm{~min}$ utes: a systematic review of the literature and hospital-based cohort. Am J Obstet Gynecol. 2007 May; 196(5):463-5.

5 Shah PS, Shah P, Tai KFY. Chest compression and/or epinephrine at birth for preterm infants $<32$ weeks gestational age: matched cohort study of neonatal outcomes. J Perinatol. 2009 Oct 25;29(10):693-7.

6 Soraisham AS, Lodha AK, Singhal N, Aziz K, Yang J, Lee SK, et al. Neonatal outcomes following extensive cardiopulmonary resuscitation in the delivery room for infants born at less than 33 weeks gestational age. Resuscitation. 2014 Feb;85(2):238-43

7 Martin RJ, Fanaroff AA, Walsh MC. Fanaroff and Martin's neonatal-perinatal medicine: diseases of the fetus and infant. 10th ed. Philadelphia, PA: Elsevier Health Sciences; 2014.

8 Mir IN, Johnson-Welch SF, Nelson DB, Brown LS, Rosenfeld CR, Chalak LF. Placental pathology is associated with severity of neonatal encephalopathy and adverse developmental outcomes following hypothermia. Am J Obstet Gynecol. 2015 Dec;213(6):849-7.

9 Rainaldi MA, Perlman JM. Pathophysiology of birth asphyxia. Clin Perinatol. 2016 Sep; 43(3):409-22.

10 Herrera CA, Silver RM. Perinatal asphyxia from the obstetric standpoint: diagnosis and interventions. Clin Perinatol. 2016;43(3): 423-38.

11 Rani S, Chawla D, Huria A, Jain S. Risk factors for perinatal mortality due to asphyxia among emergency obstetric referrals in a tertiary hospital. Indian Pediatr. 2012;49(3):191-4.

12 Himmelmann K, Ahlin K, Jacobsson B, Cans C, Thorsen P. Risk factors for cerebral palsy in children born at term. Acta Obstet Gynecol Scand. 2011;90(10):1070-81.

13 Marshall S, Lang AM, Perez M, Saugstad OD. Delivery room handling of the newborn. J Perinat Med. 2019 Dec 18;48(1):1-10.

14 Saugstad OD, Ramji S, Rootwelt T, Vento M. Response to resuscitation of the newborn: early prognostic variables. Acta Paediatr. 2005;94(7):890-5.
15 World Health Organization. The world health report 1995: bridging the gaps. Geneva, Switzerland: World Health Organization; 1995.

16 Guidelines 2000 for cardiopulmonary resuscitation and emergency cardiovascular care. Part 11: neonatal resuscitation. The American Heart Association in collaboration with the International Liaison Committee on Resuscitation. Circulation. 2000;102(8 Suppl):I-34357.

17 Saugstad OD. Delivery room management of term and preterm newly born infants. Neonatology. 2015 Jun 5;107(4):365-71.

18 Perlman JM, Wyllie J, Kattwinkel J, Wyckoff MH, Aziz K, Guinsburg R, et al. Part 7: neonatal resuscitation: 2015 international consensus on cardiopulmonary resuscitation and emergency cardiovascular care science with treatment recommendations. Resuscitation. 2015;95:e169-1.

19 Madar J, Roehr CC, Ainsworth S, Ersdal H, Morley C, Rüdiger M, et al. European resuscitation council guidelines 2021: newborn resuscitation and support of transition of infants at birth. Resuscitation. 2021 Apr;161: 291-326.

20 Polglase GR, Blank DA, Barton SK, Miller SL, Stojanovska V, Kluckow M, et al. Physiologically based cord clamping stabilises cardiac output and reduces cerebrovascular injury in asphyxiated near-term lambs. Arch Dis Child Fetal Neonatal Ed. 2018 Nov; 103(6):F530-8. 
21 Gomersall J, Berber S, Middleton P, McDonald SJ, Niermeyer S, El-Naggar W, et al. Umbilical cord management at term and late preterm birth: a meta-analysis. Pediatrics. 2021 Mar 25;147(3):e2020015404.

22 Padilla-Sánchez C, Baixauli-Alacreu S, Cañada-Martínez AJ, Solaz-García Á, AlemanyAnchel MJ, Vento M. Delayed vs immediate cord clamping changes oxygen saturation and heart rate patterns in the first minutes after birth. J Pediatr. 2020 Dec;227:149-56.e1.

23 Erickson-Owens DA, Mercer JS, Oh W. Umbilical cord milking in term infants delivered by cesarean section: a randomized controlled trial. J Perinatol. 2012 Aug 17;32(8):580-4.

24 Katheria A, Mercer J, Brown M, Rich W, Baker K, Harbert M, et al. Umbilical cord milking at birth for term newborns with acidosis: neonatal outcomes. J Perinatol. 2018 Mar 12; 38(3):240-4.

25 Girish M, Jain V, Dhokane R, Gondhali SB, Vaidya A, Aghai ZH. Umbilical cord milking for neonates who are depressed at birth: a randomized trial of feasibility. J Perinatol. 2018; 38(9):1190-6

26 Bhatt S, Alison BJ, Wallace EM, Crossley KJ, Gill AW, Kluckow M, et al. Delaying cord clamping until ventilation onset improves cardiovascular function at birth in preterm lambs. J Physiol. 2013 Apr;591(8):2113-26.

27 Bhatt S, Polglase GR, Wallace EM, te Pas AB, Hooper SB. Ventilation before umbilical cord clamping improves the physiological transition at birth. Front Pediatr. 2014 Oct 20;2:113.

28 Andersson O, Rana N, Ewald U, Målqvist M, Stripple G, Basnet O, et al. Intact cord resuscitation versus early cord clamping in the treatment of depressed newborn infants during the first 10 minutes of birth (Nepcord III): a randomized clinical trial. Matern $\mathrm{Heal} \mathrm{Neo-}$ natol Perinatol. 2019;5(1):1-11.

29 Wyckoff MH, Aziz K, Escobedo MB, Kapadia VS, Kattwinkel J, Perlman JM, et al. Part 13: neonatal resuscitation: 2015 American Heart Association guidelines update for cardiopulmonary resuscitation and emergency cardiovascular care. Circulation. 2015;132(18): S543-60.

30 O'Donnell CPF, Kamlin COF, Davis PG, Carlin JB, Morley CJ. Interobserver variability of the 5-minute Apgar score. J Pediatr. 2006 Oct; 149(4):486-9.

31 Kamlin COF, O’Donnell CPF, Everest NJ, Davis PG, Morley CJ. Accuracy of clinical assessment of infant heart rate in the delivery room. Resuscitation. 2006 Dec;71(3):319-21.

32 Hawkes G, Hawkes C, Kenosi M, Demeulemeester J, Livingstone V, Ryan C, et al. Auscultate, palpate and tap: time to re-evaluate. Acta Paediatr. 2016 Feb;105(2):178-82.

33 Kamlin CO, Dawson JA, O’Donnell CP, Morley CJ, Donath SM, Sekhon J, et al. Accuracy of pulse oximetry measurement of heart rate of newborn infants in the delivery room. J Pediatr. 2008 Jun;152(6):756-60.
34 Saugstad OD, Soll RF. Assessing heart rate at birth: auscultation is still the gold standard. Neonatology. 2016;110(3):238-40.

35 Luong D, Cheung PY, Barrington KJ, Davis PG, Unrau J, Dakshinamurti S, et al. Cardiac arrest with pulseless electrical activity rhythm in newborn infants: a case series. Arch Dis Child Fetal Neonatal Ed. 2019;104(6):F572-4.

36 Sillers L, Handley SC, James JR, Foglia EE. Pulseless electrical activity complicating neonatal resuscitation. Neonatology. 2019; 115(2):95-8.

37 Solevåg $\mathrm{AL}$, Luong $\mathrm{D}$, Lee $\mathrm{TF}$, O’Reilly $\mathrm{M}$, Cheung PY, Schmölzer GM. Non-perfusing cardiac rhythms in asphyxiated newborn piglets. PLoS One. 2019;14(4):e0214506-10.

38 Luong DH, Cheung P-Y, O’Reilly M, Lee T-F, Schmolzer GM. Electrocardiography vs. Auscultation to assess heart rate during cardiac arrest with pulseless electrical activity in newborn infants. Front Pediatr. 2018 Nov 27;6: 366-4.

39 Patel S, Cheung PY, Solevåg AL, Barrington KJ, Kamlin COF, Davis PG, et al. Pulseless electrical activity: a misdiagnosed entity during asphyxia in newborn infants? Arch Dis Child Fetal Neonatal Ed. 2019;104(2):F215-7.

40 Myerburg RJ, Halperin H, Egan DA, Boineau R, Chugh SS, Gillis AM, et al. Pulseless electric activity: definition, causes, mechanisms, management, and research priorities for the next decade: report from a National heart, lung, and blood institute workshop. Circulation. 2013 Dec;128(23):2532-41

41 Saugstad OD, Robertson NJ, Vento M. A critical review of the 2020 International Liaison Committee on Resuscitation treatment recommendations for resuscitating the newly born infant. Acta Paediatr. 2021 Apr 20; 110(4):1107-12.

42 Dawson JA, Kamlin COF, Wong C, Te Pas $A B$, Vento $M$, Cole TJ, et al. Changes in heart rate in the first minutes after birth. Arch Dis Child Fetal Neonatal Ed. 2010;95(3):F177.

43 Schmölzer GM, Hooper SB, Wong C, Kamlin COF, Davis PG. Exhaled carbon dioxide in healthy term infants immediately after birth. J Pediatr. 2015;166(4):844-3.

44 Blank DA, Gaertner VD, Kamlin COF, Nyland K, Eckard NO, Dawson JA, et al. Respiratory changes in term infants immediately after birth. Resuscitation. 2018 Sep;130:105-10.

45 Hooper SB, Fouras A, Siew ML, Wallace MJ, Kitchen MJ, te Pas AB, et al. Expired CO2 levels indicate degree of lung aeration at birth. PLoS One. 2013 Aug 12;8(8):e70895.8

46 Nicoll J, Cheung PY, Aziz K, Rajani V, O’Reilly M, Pichler G, et al. Exhaled carbon dioxide and neonatal breathing patterns in preterm infants after birth. J Pediatr. 2015; 167(4):829-33.e1.

47 American Academy of Pediatrics and American Heart Association. Textbook of neonatal resuscitation. 7th ed. AAP/AHA; 2016.
48 Espinoza ML, Cheung P-Y, Lee T-F, O’Reilly M, Schmölzer GM. Heart rate changes during positive pressure ventilation after asphyxiainduced bradycardia in a porcine model of neonatal resuscitation. Arch Dis Child Fetal Neonatal Ed. 2019 Jan;104(1):F98-101.

49 Saugstad OD, Rootwelt T, Aalen O. Resuscitation of asphyxiated newborn infants with room air or oxygen: an international controlled trial: the Resair 2 study. Pediatrics. 1998;102(1):e1.

50 Dawson JA, Schmölzer GM, Kamlin CO, te Pas AB, O'Donnell CP, Donath SM, et al. Oxygenation with $\mathrm{T}$-piece versus self-inflating bag for ventilation of extremely preterm infants at birth: a randomized controlled trial. J Pediatr. 2011 Jun;158(6):912-8.e1-2.

51 Szyld E, Aguilar A, Musante GA, Vain N, Prudent L, Fabres J, et al. Comparison of devices for newborn ventilation in the delivery room. J Pediatr. 2014 Aug;165(2):234-9.e3.

52 Roehr CC, Davis PG, Weiner GM, Jonathan Wyllie J, Wyckoff MH, Trevisanuto D. Tpiece resuscitator or self-inflating bag during neonatal resuscitation: a scoping review. $\mathrm{Pe}$ diatr Res. 2021;89(4):760-6.

53 Paz P, Ramanathan R, Hernandez R, Biniwale $M$. Neonatal resuscitation using a nasal cannula: a single-center experience. Am J Perinatol. 2014;31(12):1031-6.

54 Wood FE, Morley CJ, Dawson JA, Kamlin COF, Owen LS, Donath S, et al. Improved techniques reduce face mask leak during simulated neonatal resuscitation: study 2 . Arch Dis Child Fetal Neonatal Ed. 2008;93(3):F230.

55 Schmölzer GM, Dawson JA, Kamlin COF, O’Donnell CPF, Morley CJ, Davis PG. Airway obstruction and gas leak during mask ventilation of preterm infants in the delivery room. Arch Dis Child Fetal Neonatal Ed. 2011;96(4): F254-7.

56 Finer NN, Rich W, Wang C, Leone T. Airway obstruction during mask ventilation of very low birth weight infants during neonatal resuscitation. Pediatrics. 2009 Mar 1;123(3): 865-9.

57 Mangat A, Bruckner M, Schmölzer GM. Face mask versus nasal prong or nasopharyngeal tube for neonatal resuscitation in the delivery room: a systematic review and meta-analysis. Arch Dis Child Fetal Neonatal Ed. doi: 10.1136/archdischild-2020-319460.

58 Crawshaw JR, Kitchen MJ, Binder-Heschl C, Thio M, Wallace MJ, Kerr LT, et al. Laryngeal closure impedes non-invasive ventilation at birth. Arch Dis Child Fetal Neonatal Ed. 2018; 103(2):F112-9.

59 van Vonderen JJ, Hooper SB, Hummler HD, Lopriore E, te Pas AB. Effects of a sustained inflation in preterm infants at birth. J Pediatr. 2014 Nov;165(5):903-8.e1.

60 Klingenberg C, Sobotka KS, Ong T, Allison BJ, Schmölzer GM, Moss TJM, et al. Effect of sustained inflation duration; resuscitation of near-term asphyxiated lambs. Arch Dis Child Fetal Neonatal Ed. 2013 May;98(3):F222-7.
Delivery Room Management of

Asphyxiated Infants
Neonatology 2021;118:487-499

DOI: $10.1159 / 000516429$ 
61 Sobotka KS, Hooper SB, Crossley KJ, Ong T, Schmölzer GM, Barton SK, et al. Single sustained inflation followed by ventilation leads to rapid cardiorespiratory recovery but causes cerebral vascular leakage in asphyxiated nearterm lambs. PLoS One. 2016 Jan 14. 11(11): e0146574

62 Kamlin COF, Schmölzer GM, Dawson JA, McGrory L, O'Shea J, Donath SM, et al. A randomized trial of oropharyngeal airways to assist stabilization of preterm infants in the delivery room. Resuscitation. 2019 Nov; $144(\mathrm{Au}-$ gust):106-14.

63 Qureshi MJ, Kumar M. Laryngeal mask airway versus bag-mask ventilation or endotracheal intubation for neonatal resuscitation. Cochrane Database Syst Rev. 2018;3(3): CD003314.

64 Pejovic NJ, Trevisanuto D, Lubulwa C, Höök SM, Cavallin F, Byamugisha J, et al. Neonatal resuscitation using a laryngeal mask airway: a randomised trial in Uganda. Arch Dis Child. 2018;103(3):255-60.

65 Pejovic NJ, Trevisanuto D, Nankunda J, Tylleskär T. Pilot manikin study showed that a supraglottic airway device improved simulated neonatal ventilation in a low-resource setting. Acta Paediatr. 2016 Dec 10;105(12):1440-3.

66 Pejovic NJ, Myrnerts Höök S, Byamugisha J, Alfvén T, Lubulwa C, Cavallin F, et al. A randomized trial of laryngeal mask airway in neonatal resuscitation. N Engl J Med. 2020; 383(22):2138-47.

67 Vento M, Asensi M, Sastre J, García-Sala F, Viña J. Six years of experience with the use of room air for the resuscitation of asphyxiated newly born term infants. Biol Neonate. 2001; 79(3-4):261-7.

68 Saugstad OD, Rootwelt T, Aalen O. Resuscitation of asphyxiated newborn infants with room air or oxygen: an international controlled trial: the Resair 2 Study. Pediatrics. 1998 Jul 1;102(1):e1.

69 Vento M, Sastre J, Asensi MA, Viña J. Roomair resuscitation causes less damage to heart and kidney than 100\% oxygen. Am J Respir Crit Care Med. 2005 Dec;172(11):1393-8.

70 Vento M, Asensi M, Sastre J, Lloret A, GarcíaSala F, Viña J. Oxidative stress in asphyxiated term infants resuscitated with $100 \%$ oxygen. J Pediatr. 2003 Mar;142(3):240-6.

71 Wyllie J, Bruinenberg J, Roehr CC, Rüdiger M, Trevisanuto D, Urlesberger B. European resuscitation council guidelines for resuscitation 2015. Section 7. Resuscitation and support of transition of babies at birth. Resuscitation. 2015;95:249-63.

72 Sweet DG, Carnielli V, Greisen G, Hallman M, Ozek E, Te Pas A, et al. European consensus guidelines on the management of respiratory distress syndrome: 2019 update. Neonatology. 2019;115(4):432-50.

73 Davis PG, Tan A, O’Donnell CP, Schulze A. Resuscitation of newborn infants with $100 \%$ oxygen or air: a systematic review and metaanalysis. Lancet. 2004 Oct;364(9442):132933.
74 Saugstad OD. Resuscitation of newborn infants: from oxygen to room air. Lancet. 2010 Dec;376(9757):1970-1.

75 Solevåg AL, Dannevig I, Wyckoff M, Saugstad OD, Nakstad B. Extended series of cardiac compressions during CPR in a swine model of perinatal asphyxia. Resuscitation. 2010 Nov; 81(11):1571-6.

76 Solevag AL, Dannevig I, Wyckoff M, Saugstad OD, Nakstad B. Return of spontaneous circulation with a compression:ventilation ratio of 15:2 versus $3: 1$ in newborn pigs with cardiac arrest due to asphyxia. Arch Dis Child Fetal Neonatal Ed. 2011 Nov 1;96(6):F417-21.

77 Pasquin MP, Cheung P-Y, Patel S, Lu M, Lee T-F, Wagner M, et al. Comparison of different compression to ventilation ratios $(2: 1,3$ : 1 , and $4: 1$ ) during cardiopulmonary resuscitation in a porcine model of neonatal asphyxia. Neonatology. 2018;114(1):37-45.

78 Schmölzer GM, O’Reilly M, LaBossiere J, Lee TF, Cowan S, Nicoll J, et al. 3:1 Compression to ventilation ratio versus continuous chest compression with asynchronous ventilation in a porcine model of neonatal resuscitation. Resuscitation. 2014;85(2):270-5.

79 Babbs CF, Meyer A, Nadkarni V, Neonatal CPR. Neonatal CPR: room at the top: a mathematical study of optimal chest compression frequency versus body size. Resuscitation. 2009 Nov;80(11):1280-4.

80 Li ES, Cheung P-Y, Lee TF, Lu M, O’Reilly M, Schmölzer GM. Return of spontaneous circulation is not affected by different chest compression rates superimposed with sustained inflations during cardiopulmonary resuscitation in newborn piglets. PLoS One. 2016 Jun 15;11(6): 0157249

81 Patel S, Cheung P-Y, Lee T-F, Pasquin MP, Lu M, O'Reilly M, et al. Asynchronous ventilation at 120 compared with 90 or 100 compressions per minute improves haemodynamic recovery in asphyxiated newborn piglets. Arch Dis Child Fetal Neonatal Ed. 2020 Jul; 105(4):357-63.

82 Meyer A, Nadkarni V, Pollock A, Babbs C, Nishisaki A, Braga M, et al. Evaluation of the neonatal resuscitation program's recommended chest compression depth using computerized tomography imaging. Resuscitation. 2010;81(5):544-8

83 Saini SS, Gupta N, Kumar P, Bhalla AK, Kaur $\mathrm{H}$. A comparison of two-fingers technique and two-thumbs encircling hands technique of chest compression in neonates. J Perinatol. 2012 Sep 17;32(9):690-4.

84 Christman C, Hemway RJ, Wyckoff $\mathrm{MH}$, Perlman JM. The two-thumb is superior to the two-finger method for administering chest compressions in a manikin model of neonatal resuscitation. Arch Dis Child Fetal Neonatal Ed. 2011 Mar 1;96(2):F99-101.

85 Menegazzi JJ, Auble TE, Nicklas KA, Hosack GM, Rack L, Goode JS. Two-thumb versus two-finger chest compression during CRP in a swine infant model of cardiac arrest. Ann Emerg Med. 1993 Feb;22(2):240-3.
86 Garcia-Hidalgo C, Cheung P-Y, Solevåg AL, Vento M, O'Reilly M, Saugstad O, et al. A review of oxygen use during chest compressions in newborns-A meta-analysis of animal data. Front Pediatr. 2018 Dec;6:400-7.

87 Solevåg AL, Garcia-Hidalgo C, Cheung PY, Lee TF, O’Reilly M, Schmölzer GM. Ventilation with 18,21 , or $100 \%$ oxygen during cardiopulmonary resuscitation of asphyxiated piglets: a randomized controlled animal trial. Neonatology. 2020;117(1):102-10.

88 Hidalgo CG, Solevag AL, Kim SY, Shim GH, Cheung P-Y, Lee T-F, et al. Sustained inflation with $21 \%$ versus $100 \%$ oxygen during cardiopulmonary resuscitation of asphyxiated newborn piglets - A randomized controlled animal study. Resuscitation. 2020 Oct; 155:39-47.

89 Schmölzer GM, O’Reilly M, Labossiere J, Lee TF, Cowan S, Qin S, et al. Cardiopulmonary resuscitation with chest compressions during sustained inflations: a new technique of neonatal resuscitation that improves recovery and survival in a neonatal porcine model. Circulation. 2013;128(23):2495-503.

90 Schmölzer GM, O Reilly M, Fray C, van Os S, Cheung P-Y. Chest compression during sustained inflation versus $3: 1$ chest compression: ventilation ratio during neonatal cardiopulmonary resuscitation: a randomised feasibility trial. Arch Dis Child Fetal Neonatal Ed. 2018 Sep;103(5):F455-60.

91 Schmölzer GM, Pichler G, Solevåg AL, Fray C, van Os S, Cheung P-Y. The SURV1VE trial: sustained inflation and chest compression versus 3:1 chest compression-to-ventilation ratio during cardiopulmonary resuscitation of asphyxiated newborns: study protocol for a cluster randomized controlled trial. Trials. 2019 Dec 19;20(1):139.

92 Schwindt EM, Hoffmann F, Deindl P, Waldhoer TJ, Schwindt JC. Duration to establish an emergency vascular access and how to accelerate it: a simulation-based study performed in real-life neonatal resuscitation rooms. Pediatr Crit Care Med. 2018;19(5):468-76.

93 Wagner M, Olischar M, O’Reilly M, Goeral K, Berger A, Cheung PY, et al. Review of routes to administer medication during prolonged neonatal resuscitation. Pediatr Crit Care Med. 2018;19(4):332-8.

94 Baik-Schneditz N, Pichler G, Schwaberger B, Mileder L, Avian A, Urlesberger B. Peripheral intravenous access in preterm neonates during postnatal stabilization: feasibility and safety. Front Pediatr. 2017 Aug 10;5:171.

95 Maconochie IK, Bingham R, Eich C, LópezHerce J, Rodríguez-Núñez A, Rajka T, et al. European resuscitation council guidelines for resuscitation 2015: section 6. Paediatric life support. Resuscitation. 2015 Oct;95:223-48.

96 Scrivens A, Reynolds PR, Emery FE, Roberts CT, Polglase GR, Hooper SB, et al. Use of intraosseous needles in neonates: a systematic review. Neonatology. 2019;116(4):305-14. 
97 Mogale N, Van Schoor A-N, Bosman MC. A theoretical alternative intraosseous infusion site in severely hypovolemic children. Afr J Prim Health Care Fam Med. 2015 Jul 23;7(1).

98 Fuchs Z, Scaal M, Haverkamp H, Koerber F, Persigehl T, Eifinger F. Anatomical investigations on intraosseous access in stillborns - Comparison of different devices and techniques. Resuscitation. 2018 Jun;127:79-82.

99 Mileder LP, Urlesberger B, Schwaberger B. Use of intraosseous vascular access during neonatal resuscitation at a tertiary center. Front Pediatr. 2020;8(September):5712855.

100 Borrhomée S, Merbouche S, Kern-Duciau $\mathrm{N}$, Boize P. Umbilical vein catheterization through Wharton's jelly: a possibility for a fast and safe way to deliver treatments in the delivery room? Arch Pediatr. 2019;26(6): 381-4.

101 O'reilly M, Schmölzer GM. Evidence for vasopressors during cardiopulmonary resuscitation in newborn infants. Minerva Pediatr. 2019 Feb;71(2):159-73.

102 Isayama T, Mildenhall L, Schmölzer GM, Kim H-S, Rabi Y, Ziegler C, et al. The route, dose, and interval of epinephrine for neonatal resuscitation: a systematic review. Pediatrics. 2020 Oct 9;146(4):e20200586.

103 Chiruvolu A, Miklis KK, Chen E, Petrey B, Desai S. Delivery room management of meconium-stained newborns and respiratory support. Pediatrics. 2018;142(6):e20181485.

104 Fischer C, Rybakowski C, Ferdynus C, Sagot P, Gouyon JB. A population-based study of meconium aspiration syndrome in neonates born between 37 and 43 weeks of gestation. Int J Pediatr. 2012;2012:321545-7.

105 Moses D, Holm BA, Spitale P, Liu M, Enhorning $\mathrm{G}$. Inhibition of pulmonary surfactant function by meconium. Am J Obstet Gynecol. 1991 Feb;164(2):477-81.

106 Vidyasagar D, Zagariya A. Studies of meconium-induced lung injury: inflammatory cytokine expression and apoptosis. J Perinatol. 2008 Dec 5;28(Suppl 3):S102-7.

107 Edwards EM, Lakshminrusimha S, Ehret DEY, Horbar JD. NICU admissions for meconium aspiration syndrome before and after a National Resuscitation Program Suctioning Guideline Change. Children. 2019; 6(5):68.

108 Kalra VK, Lee HC, Sie L, Ratnasiri AW, Underwood MA, Lakshminrusimha S. Change in neonatal resuscitation guidelines and trends in incidence of meconium aspiration syndrome in California. J Perinatol. 2020; 40(1):46-55.
109 Oommen VI, Ramaswamy VV, Szyld E, Roehr CC. Resuscitation of non-vigorous neonates born through meconium-stained amniotic fluid: post policy change impact analysis. Arch Dis Child Fetal Neonatal Ed. 2020 Sep 22;fetalneonatal-2020-319771.

110 Trevisanuto D, Strand ML, Kawakami MD, Fabres J, Szyld E, Nation K, et al. Tracheal suctioning of meconium at birth for nonvigorous infants: a systematic review and meta-analysis. Resuscitation. 2020;149(November 2019):117-26.

111 Phattraprayoon N, Tangamornsuksan W, Ungtrakul T. Outcomes of endotracheal suctioning in non-vigorous neonates born through meconium-stained amniotic fluid: a systematic review and meta-analysis. Arch Dis Child Fetal Neonatal Ed. 2021 Jan; 106(1):31-8.

112 Jacobs SE, Hunt R, Tarnow-Mordi WO, Inder TE, Davis PG. Cooling for newborns with hypoxic ischaemic encephalopathy. In: Jacobs SE, editor. Cochrane database of systematic reviews. Chichester, UK: John Wiley \& Sons, Ltd; 2007.

113 Daetwyler K, Brotschi B, Berger TM, Wagner BP. Feasibility and safety of passive cooling in a cohort of asphyxiated newborn infants. Swiss Med Wkly. 2013;143(March): w13767-6.

114 Mortola JP. Implications of hypoxic hypometabolism during mammalian ontogenesis. Respir Physiol Neurobiol. 2004 Aug; 141(3):345-56

115 Burnard ED, Cross KW. Rectal temperature in the newborn after birth asphyxia. Br Med J. 1958 Nov 15;2(5106):1197-9.

116 Jacobs SE, Morley CJ, Inder TE, Stewart MJ, Smith KR, McNamara PJ, et al. Whole-body hypothermia for term and near-term newborns with hypoxic-ischemic encephalopathy: a randomized controlled trial. Arch Pediatr Adolesc Med. 2011 Aug 1;165(8):692.

117 O'Reilly D, Labrecque M, O’Melia M, Bacic J, Hansen A, Soul JS. Passive cooling during transport of asphyxiated term newborns. J Perinatol. 2013;33(6):435-40.

118 Lemyre B, Ly L, Chau V, Chacko A, Barrowman $\mathrm{N}$, Whyte $\mathrm{H}$, et al. Initiation of passive cooling at referring centre is most predictive of achieving early therapeutic hypothermia in asphyxiated newborns. Paediatr Child Health. 2017;22(5):264-8.
119 Carreras N, Alsina M, Alarcon A, Arca-Díaz G, Agut T, García-Alix A. Efficacy of passive hypothermia and adverse events during transport of asphyxiated newborns according to the severity of hypoxic-ischemic encephalopathy. J Pediatr. 2018;94(3):251-7.

120 Akula VP, Joe P, Thusu K, Davis AS, Tamaresis JS, Kim S, et al. A randomized clinical trial of therapeutic hypothermia mode during transport for neonatal encephalopathy. J Pediatr. 2015;166(4):856-2.

121 Prashantha YN, Suman Rao PN, Nesargi S Chandrakala BS, Balla KC, Shashidhar A. Therapeutic hypothermia for moderate and severe hypoxic ischaemic encephalopathy in newborns using low-cost devices - ice packs and phase changing material. Paediatr Int Child Health. 2019 Oct 2;39(4):234-9.

122 Wang H, Bhutta ZA, Coates MM, Coggeshall M, Dandona L, Diallo K, et al. Global, regional, national, and selected subnational levels of stillbirths, neonatal, infant, and under-5 mortality, 1980-2015: a systematic analysis for the Global Burden of Disease Study 2015. Lancet. 2016 Oct;388(10053): 1725-74

123 Wall SN, Lee AC, Niermeyer S, English M, Keenan WJ, Carlo W, et al. Neonatal resuscitation in low-resource settings: what, who, and how to overcome challenges to scale up? Int J Gynaecol Obstet. 2009 Oct;107(Suppl 1):S47-4.

124 UNICEF, WHO WBG and UN. Levels and trends in child mortality 2020. Estimates developed by the UN Inter-agency group for child mortality estimation. Available from: https://www.unicef.org/reports/levels-andtrends-child-mortality-report-2020

125 Moshiro R, Mdoe P, Perlman JM. A global view of neonatal asphyxia and resuscitation. Front Pediatr. 2019 Nov 26;7:489.

126 Gilstrap LC, Leveno KJ, Burris J, Lynne Williams M, Little BB. Diagnosis of birth asphyxia on the basis of fetal $\mathrm{pH}$, Apgar score, and newborn cerebral dysfunction. Am J Obstet Gynecol. 1989 Sep;161(3):825-30.

127 Versantvoort JMD, Kleinhout MY, Ockhuijsen HDL, Bloemenkamp K, De Vries WB, Van Den Hoogen A. Helping babies breathe and its effects on intrapartum-related stillbirths and neonaatal mortality in low-resource settings: a systematic review. Arch Dis Child. 2020;105(2):127-33.

128 Foglia EE, Weiner G, de Almeida MFB, Wyllie J, Wyckoff MH, Rabi Y, et al. Duration of resuscitation at birth, mortality, and neurodevelopment: a systematic review. Pediatrics. 2020;146(3):e20201449.
Delivery Room Management of

Asphyxiated Infants
Neonatology 2021;118:487-499

DOI: $10.1159 / 000516429$ 